\title{
Supplementary figures
}
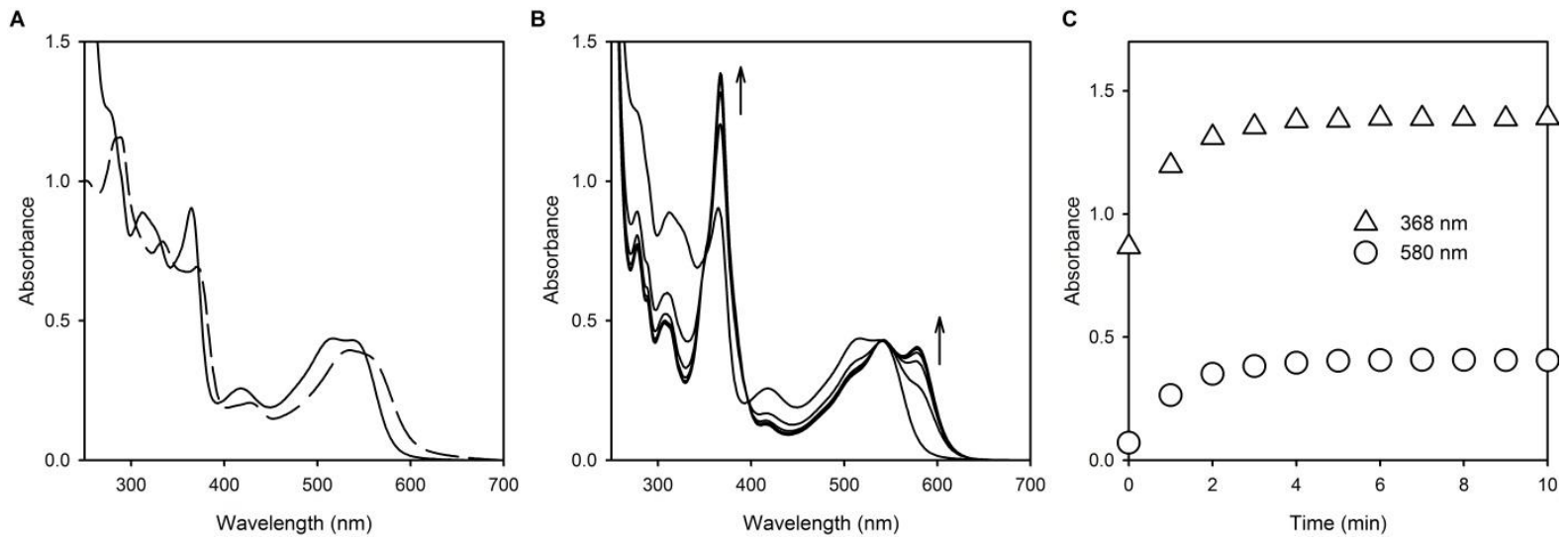

Supplementary figure 1. Reaction of GSCbl with $\mathrm{SO}_{3}{ }^{2-}$. Absorption spectra were recorded for the reaction of $50 \mu \mathrm{M} \mathrm{GSCbl}$ with $100 \mathrm{mM} \mathrm{SO}_{3}{ }^{2-}$ in $50 \mathrm{mM}$ CHES pH 10.0. (A), the absorption spectrum for GSCbl (dashed line) and for the reaction immediately after initiation (solid line) by the addition of $\mathrm{SO}_{3}{ }^{2-}$. (B), absorption spectra at every 1 min of incubation after (A). Arrows indicate the absorption increases at $368 \mathrm{~nm}$ and $580 \mathrm{~nm}$, which are characteristic of diCNCbl generation. (C), Changes in A360 $\mathrm{nm}$ and $\mathrm{A} 580 \mathrm{~nm}$ following the incubation time. 

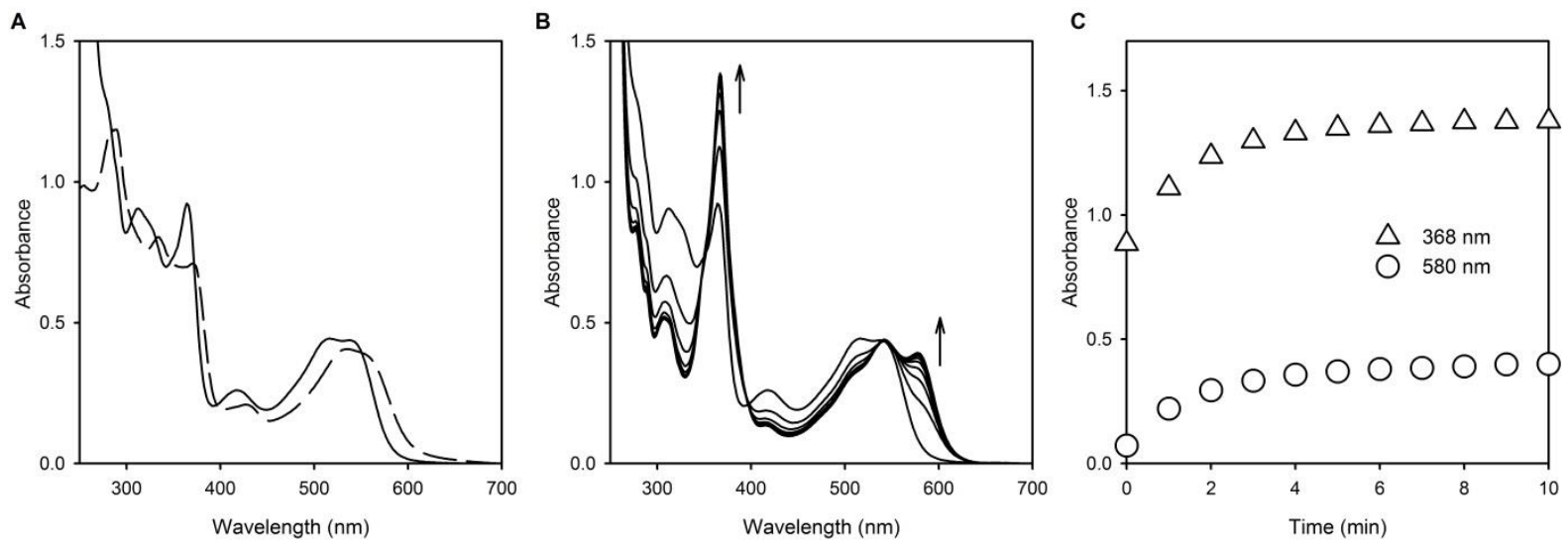

Supplementary figure 2. Reaction of GSCbl with $\mathbf{H S O}_{3}$. Absorption spectra were recorded for the reaction of $50 \mu \mathrm{M} \mathrm{GSCbl}$ with $100 \mathrm{mM} \mathrm{HSO}_{3}{ }^{-}$in $50 \mathrm{mM} \mathrm{CHES} \mathrm{pH} \mathrm{10.0.} \mathrm{(A),} \mathrm{the} \mathrm{absorption} \mathrm{spectrum}$ for GSCbl (dashed line) and for the reaction immediately after initiation (solid line) by the addition of $\mathrm{HSO}_{3}{ }^{-}$. (B), absorption spectra at every 1 min of incubation after (A). Arrows indicate the absorption increases at $368 \mathrm{~nm}$ and $580 \mathrm{~nm}$, which are characteristic of diCNCbl generation. (C), Changes in A360 $\mathrm{nm}$ and A580 $\mathrm{nm}$ following the incubation time. 